\title{
A field study of team working in a new human supervisory control system
}

\author{
N. A. STANTON ${ }^{2}$ * and M. J. ASHLEIGH
}

\begin{abstract}
This paper presents a case study of an investigation into team behaviour in an energy distribution company. The main aim was to investigate the impact of major changes in the company on system performance, comprising human and technical elements. A sociotechnical systems approach was adopted. There were main differences between the teams investigated in the study: the time of year each control room was studied (i.e. summer or winter),the stage of development each team was in (i.e. $<3$ months or $>10$ months), and the team structure (i.e. hierarchical or heterarchical). In all other respects the control rooms were the same: employing the same technology and within the same organization. The main findings were: the teams studied in the winter months were engaged in more 'planning' and 'awareness' type of activities than those studies in the summer months. Newer teams seem to be engaged in more sharing of information than older teams, which maybe indicative of the development process. One of the hierarchical teams was engaged in more 'system-driven' activities than the heterarchical team studied at the same time of year. Finally, in general, the heterarchical team perceived a greater degree of team working culture than its hierarchical counterparts. This applied research project confirms findings from laboratory research and emphasizes the importance of involving ergonomics in the design of team working in human supervisory control.
\end{abstract}

Keywords: Control rooms; Team structure; Team culture; Systems analysis.

*Author for correspondence.e-mail:neville.stanton@brunel.ac.uk 


\section{Introduction}

Energy transportation companies in the UK have undergone some major organizational changes. Since the demergers, they have been transformed from public utilities into private commercial companies. Inevitably this has required the organization to become even more efficient in its operation to compete in the commercial world. These changes, among others, have had a dramatic effect upon the organizational culture, and the operational climate has changed accordingly. Changes within an energy transportation company in the UK include the replacement of 12 individual regions with four areas (North, South, East, West), each replacing three former regions. North and East Area Control Centres (ACC) were commissioned in October 1995. West was commissioned in June 1996 and South ACC was commissioned in July 1996. One of the main problems for the four new areas was overcoming the diversity in operational practices to reach an agreed code of practice within, and between, each ACC. The new ACC made use of new technology, both for human supervisory control systems (i.e. system control and data acquisition systems, SCADA) and for tasks traditionally done with pen and paper(e.g. memos were now to be sent using electronic applications). The main aims of this research were to understand some of this diversity, identify the implications of different ways of working, and to indicate mechanisms for best practice.

To cope with the complexity of assessing team activity, the research was addressed within a general 'systems' paradigm (vonBertalanffy1950). A growing interest in the ideas behind the socio-technical approach to system evaluation is evident in the research literature (Ackoff and Emery 1972, Lockett and Spear 1980). The socio-technical approach identifies two major subsystems, the technical system (hardware and software), and the social system (engineers, control room staff, management, etc.).This analysis reflects the realisation that the interaction between both of these systems needs to be considered. As Woods (1987) writes, control rooms are neither technical systems nor just human systems. In particular, it is the nature of the interaction between the social and technical subsystems that provides the greatest insight into performance and potential problems. Hettenhaus (1992) considers that a socio-technical approach should address:

- the technical process;

- the interaction of operators with the technical process;

- the interaction of people with each other; and

- the boundaries of management within the system.

He suggested that the technology could be employed to enable people to work at a higher level. The systems approach has been previously applied in team work research, for analysing team working in aviation (Foushee and Helmreich 1988), inter-group relations (Guzzo and Shea 1992) and innovation in management teams (West and Anderson 1996). All three of these studies identify the three main factors in socio-technical systems as: inputs, process and outputs. 'Inputs' identify those factors brought to the team situation: the characteristics of the individuals within the team, the characteristics of the team and the characteristics of the environment. 'Process' refers to those factors relating to the functioning of the team: interaction between team members, exchange of information, coordination, and decision making. 'Outputs' refers to the performance of the team in terms of the task and satisfactions of team members. The variables within each of the main factors are presented in table 1 . On the basis of the research approaches identified in table 1, the general systems framework looked most appropriate for research into teams in control rooms.

\section{Development of methodology}

The methodology for the project was determined from a review of the team working literature (Stanton 1996), previous studies using systems approaches (table 1), and a pilot study conducted by the researchers to determine the efficacy of the methods (Ashleigh and Stanton 1997). Within a general systems framework, variables, and their corresponding measures, were developed which were appropriate to the analysis of team activity in control centres. In 


\begin{tabular}{|c|c|c|c|}
\hline Reference & Inputs & Process & Outputs \\
\hline Foushee and helmreich (1988) & $\begin{array}{l}\text { Individual: skills, abilities, etc } \\
\text { Group: structure, size, etc. } \\
\text { Environment: technological } \\
\text { support, task design, etc. }\end{array}$ & $\begin{array}{l}\text { Exchange of information, } \\
\text { coordination, participation, } \\
\text { consensus, decision-making }\end{array}$ & $\begin{array}{l}\text { Task-related: safety, } \\
\text { efficiency, productivity, } \\
\text { quality } \\
\text { Group-related: } \\
\text { satisfaction, attitudes }\end{array}$ \\
\hline Guzzo and Shea (1992) & $\begin{array}{l}\text { Knowledge, skills and abilitie: } \\
\text { Composition of the team } \\
\text { Organisational context }\end{array}$ & $\begin{array}{l}\text { Interactions among group } \\
\text { members, information } \\
\text { exchange, participation } \\
\text { in decision-making }\end{array}$ & $\begin{array}{l}\text { Group performance } \\
\text { Group well-being and } \\
\text { satisfaction of team } \\
\text { members }\end{array}$ \\
\hline West and Anderson (1996) & $\begin{array}{l}\text { Group composition: size, } \\
\text { knowledge, skills, abilities } \\
\text { Organisational context: } \\
\text { climate, support, resources }\end{array}$ & $\begin{array}{l}\text { Clarity of commitment to obje } \\
\text { participation, } \\
\text { task orientation, support for } \\
\text { innovation }\end{array}$ & $\begin{array}{l}\text { Number of innovations } \\
\text { Innovations: radicalness, } \\
\text { magnitude, novelty, } \\
\text { effectiveness }\end{array}$ \\
\hline
\end{tabular}

Table 1. Variables identified by previous research.

line with previous research, the framework of input, processes and outputs was followed. The three main factors in the systems approach were identified as:

- $\quad$ Inputs to team working (comprising the individual competencies of team members and the structure of the team).

- Team working processes (comprising physical movement around the control room, behaviour, communication in the pursuit of their work-related goals).

- $\quad$ Outputs from team working (comprising factors of task success).

These factors were assessed by a combination of direct observation, questionnaires and performance ratings by experts. The methods were developed and tested throughout the pilot study in North ACC. The main aims of the study were to test the methods. The pilot study also established the levels of reliability of the observational techniques. While observer reliability was moderate, it was suggested that this would be improved with better positioning of the video camera and more training in the behavioural categories. It was recommended that the observer reliability be checked for the main observational study. As there was no established method for collecting information on the perceptions of team working, a team working questionnaire was developed from two sources, a literature review (Stanton 1996) and a previously developed questionnaire used in the electricity supply industry (Glendon et al. 1994). The pilot study also proposed that two further questionnaires be adopted in the main study to measure the intrinsic nature of the work (Hackman and Oldham 1980) and the job satisfaction of the ACC staff (Warr et al. 1979). The most problematic aspect of the project was the derivation of some measures of ACC performance. This was resolved by the development of a questionnaire to be completed by the 32 districts and National Control Centre (NCC), which requested ratings of ACC performance. These revisions led to the final research methodology, as shown in figure 1 . In this section, the methods used are outlined.

2.1. Behavioural competencies The competencies model may best characterize inputs from the individual, such as: concern for quality, initiative, performance orientation, team working, 
developing, leadership and focus on results. Competency models aim to measure practical intelligence (Kemp and McClelland 1986, Dulewicz 1989). Their inclusion in this research was to determine any differences between calibre of people at the four ACC. These data were being collected by the organization as a matter of course. Managers rated each person in the control room along dimensions such as judgement, working together, quality, sharing and developing, and focus on results. The scores were summed to give an overall competency score for each person.

2.2. Team structure Different team structures were observed at South ACC when compared with North, East and West. In the North, East and West ACC each of the three control desk engineers (CDE) has clear delineation of responsibility for operations (i.e. the hourby-hour management of the energy distribution network and dealing with faults) and strategy(i.e. forecasting and planning for energy distribution overthefollowing24h, including preparation for system outages and reconfiguring the network)for a given local distribution zone (LDZ). The shift supervisor (SS) remains in a more strategic and supervisory role. This is contrasted with

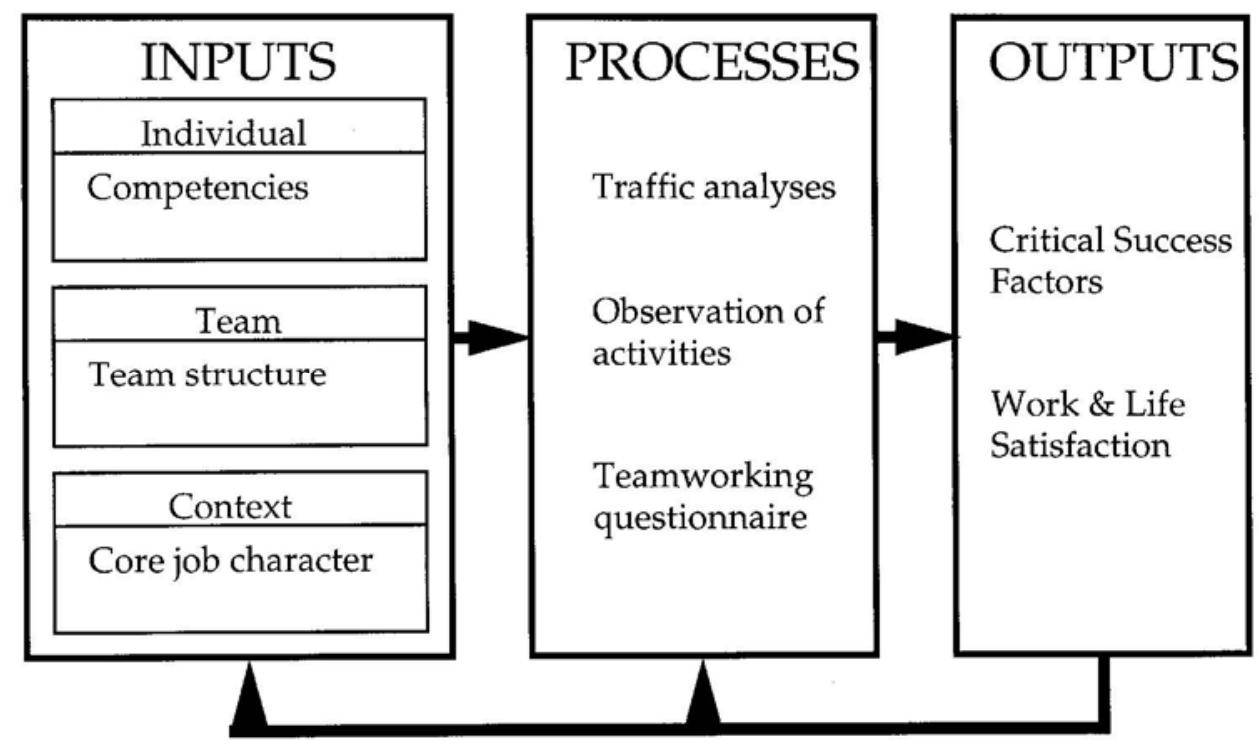

South Area where two CDE (or one CDE and one SS) share responsibility for the operations over the entire South area and two CDE (or one CDE and one SS) have responsibility for strategy. The .strategy personnel will assist with operations if task demand requires. The differentiation between the CDE and SS are less clear at South area (although the SS is still formally classed as the team leader with overall responsibility for the team). In this respect North, East and West ACC maintain a more traditional hierarchical format. Whether this has any impact upon performance of the ACC is an empirical question addressed within this project.

Figure1. Systems approach adopted for the main study. Arrow simply influence and feedback between the factors

2.3. Core job characteristics The core job characteristics model of work identifies five principal characteristics of work that may predict job performance and satisfaction. The core job characteristics are: skill variety, task identity, task significance, autonomy, and feedback. Hackman and Oldham (1980) produced a self-report questionnaire that can be used to investigate the extent to which the five core job characteristics are present in the work, and the use of this approach is widely reported in the literature. 
2.4. TraYc analysis Link charts are used to represent the physical movement of people around the ACC (Chapanis1959, Drury 1995). The analysis of movement around the ACC can be used to optimize the physical layout of the control room as well as confirming the effectiveness of current arrangements. It indicates the amount of contact each person has with other workstations and equipment in the ACC, as well as the extent to which the SS and CDE remain at their own workstation. These data may be represented in tables, pie charts and link diagrams. The position of personnel in the ACC was noted every $10 \mathrm{~min}$ by two observers and recorded on a map of the ACC. The reliability scores were also computed

2.5. Observation of activity In addition to direct (shadowing) observation, video recording of control room activities was undertaken. Videotaping offers an easy means of collecting data on behaviour, but can be time consuming to analyse. Videotape analysis systems enable activity recorded on videotape to be analysed in real-time. This is a dramatic improvement on traditional analysis approaches. The videotape study was used to test the reliability of the analysis as well as comparing the analysis with direct observation. The main categories within which activity was observed in the control room were as follows:

- Shift handover.

- Maintenance activities.

- Dealing with problems.

- Demand forecasting.

- Servicing application functions.

- Monitoring and controlling the energy system.

Within this classification of ACC context, all of the observed activities were further classified into one of five generic functions:

- PLANNING: activities that require strategic planning and driving the system such as forecasting demand, checking constraints, planning operations, issuing fault reports and completing a holder log summary.

- AWARENESS: activities that maintain an awareness of system state, monitoring stock, monitoring alarm lists, checking telemetry, monitoring demand and intake.

- SHARING: activities that share own and others knowledge of the system such as creating and editing an event log, sending e-mail or lotus notes, editing a handover log, putting information on a bulletin board, holding a discussion forum and providing training.

- OTHER: any other activity not classified under the other four categories, such as being away from the desk, social interaction and other administrative tasks.

- DRIVEN: activities that are driven by the system in real-time such as sending control instructions, answering the phone, acknowledging and analysing alarms and dealing with interruptions

There are concerns about the intrusiveness of observation, the amount of eVort required in analysing the data, the objectivity of the analysis and the comprehensiveness of the observational method. Despite these concerns, it is difficult to manage without some form of observational data, as it provides information about tasks under taken in the control room.

2.6. Team working questionnaire The attitudes of the team are as important as their activities in this study. To gauge the attitudes of the ACC team a questionnaire was developed. While it is always difficult to establish causal relationships, there is little doubt that attitudes and behaviour are linked. In recent years there has been an increase in interest in corporate 
culture as a determinant of the behaviour of individuals within the organization. No standardized team working questionnaire exists, so our own was developed comprising seven dimensions:

- CONSENSUS: where there is involvement and participation of team members to achieve unanimity in decision-making.

- COORDINATION: where tasks and procedures are standardized and documented to harmonize the team in meeting a common objective.

- CONTROL: where the appropriate tools and procedures are adequate to facilitate meeting the team's objective and where members feel a sense of responsibility and ownership of their objectives.

- COMMUNICATION: where there are adequate opportunities to exchange information both vertically and horizontally to achieve the teams objective.

- COOPERATION: where there is a willingness to share ideas, views and work together to build a cohesive team.

- COACHING: where training and support is given to enhance knowledge, skill and personal development.

- CULTURE: where organizational style, norms and values are appropriate for teamworking to develop.

The questionnaire was devised on the basis of identifying concepts relevant to team working and selecting items that are likely to measure those concepts. Initial work was based upon the performance shaping factors questionnaire developed by Glendon et al.(1994) and a review of team working by Stanton(1996). There were 68 questions in total. The respondent was required to rate each statement on a nine-point scale (from never to sometimes to always).

2.7. Critical success factors questionnaire (CSF-Q) The CSF-Q was developed from an openended questionnaire previously used within the company to assess performance. Its development was based on the desire to have some measure of the product from the ACC. In the absence of data derived from the energy transportation system, ratings were opted from people who dealt with the ACC on a regular basis. An analysis of the open responses led to the identification of seven main business areas where ACC have an impact on other parties in the energy transportation system:

- TRUST: trust in each other, sharing of ideas and information.

- UNDERSTANDING: understanding pressures, constraints and needs.

- PARTNERSHIP: relationships, exchanging views, meeting mutual objectives effectively.

- EFFICIENCY: degree to which system control appears to be innovative, reliable and efficient in both routine and non-routine situations.

- COMMUNICATION: degree to which communication lines are open, effectiveness of communications for shift handovers, faults, plant changes, requests and problems.

- HELPFULNESS: degree to which system control is approachable, dependable, courteous and cooperative.

- EFFECTIVENESS: general reliability and efficiency of system control, quality of their technical knowledge and their responsiveness to feedback.

There were 76 statements in total. The respondent was required to rate each statement on a nine-point scale (from never to sometimes to always). The questionnaire was completed by 122 people who were, in effect, the customers of the ACC. These individuals were selfselected respondents who agreed to participate in the study.

2.8. Work and life satisfaction questionnaire As well as performance, other researchers have identiffied the need to assess the satisfaction of team members in their work. A questionnaire that measures eight factors associated with job satisfaction determined the contentment of people within the ACC (Warr et al. 1979). The factors measured were: work involvement, job motivation, job satisfaction (js), total js, intrinsic js, higher order needs, life satisfaction (Is), total Is, happiness and anxiety. The data from the questionnaire provide an overview of the 
job and general life satisfaction of people within the ACC.

\section{Research methods for main study}

The main research project reported here was conducted over 18 months (February 1996 -July 1997).

3.1. Participants Participants were as follows: the main participants in the questionnaire and observation studies were CDE, SS, management and support staff at the ACC:

North $(n=30)$, South $(n=31)$, East $(n=29)$ and West $(n=36)$. Other participants were people at the area districts $(n=107)$ and national control $(n=15)$ who completed the CSF-Q. These participants were, in effect, customers of the ACC and therefore in a position to make judgements about how well each ACC performed. Anonymity of all participants in the study was guaranteed.

3.2. Design of study The design of the study enabled a comparison of the four ACC (North, South, East, West). A quasi-experimental design was possible because of the different team structure at South compared with the rest of the ACC and a comparison of the demands of summer and winter on the ACC. North and South were observed in the winter months(October1996 - February1997) and East and West were observed in the summer months (August -September 1996). Measures taken include: behavioural rating scales of competence; questionnaires onjob characteristics, teamworking, performance and job satisfaction; and observation of physical movement and activities.

3.3. Equipment The equipment used comprised a video camera, observation sheets, and five questionnaires to elicit data on human factors aspects of the SCADA system (Ravden and Johnson 1989), core job characteristics (Hackman and Oldham 1980), team working (Stanton and Ashleigh 1999), critical success factors (Stanton and Ashleigh 1999), and work and life satisfaction (Warr et al. 1979).

3.4. Procedure for study The nature of the project was introduced to all staff at the ACC. This was followed by visits by the research team. On arrival at the control rooms the questionnaires were distributed and interviews arranged. People were asked to volunteer for the observational study, and the right to withdraw was made clear. The observational study was conducted by shadowing an individual for an entire shift. Observations of the activities of each CDE/SS were undertaken over the course of six shifts, with videotaping for reliability analysis.

3.5. Statistical analysis The differences between the four ACC were explored by analysis of variance (ANOVA, non-parametric and parametric with post-hoc tests where appropriate). The ANOVA model sought to identify main effects for the independent variable of area (i.e. where differences lie between the four ACC) across each of the dependent variables in turn (e.g. behavioural competencies, core job characteristics, observed activities, critical success factors, work and life satisfaction).

\section{Results of the comparison of area control centres}

This section deals with the comparison of ACC with respect to the input, process and output structure of the systems analysis.

4.1. Inputs into area control centres The inputs into the ACC comprise individual inputs(behavioural competencies) team inputs (team structure) and contextual inputs (core job characteristics). These are presented below.

4.1.1. Individual inputs: Ratings of control room personnel were undertaken by senior managers who had received training in the behavioural competencies methodology. The results show that there were no significant differences between the $S S \operatorname{scores}\left(x^{2}=6.4, p=\right.$ ns). There were statistical diVerences between the CDE scores $(x 2=10.6, p<0.05)$ (figure 2$)$. Further analysis showed that these differences resulted from lower scores at South ACC 
compared with West $\operatorname{ACC}(Z=2.7, p<0.01)$, although visual inspection of the mean score at South ACC looks very close to that at East ACC. The lack of statistical significance is due to the difference at East not reaching the probability criterion. The means for each of the areas was: North (mean $=12.5, \mathrm{SD}=2.0)$, South $(11.2,2.2)$, East $(11.2,2.6)$ and West $(13.5,2.2)$.

The lower competency scores at South ACC may be due to possible vagaries in the methodology for assessing behavioural competencies, as different assessors are involved, or due to genuine differences in staffing at the ACC. If staff at South ACC are of a lower calibre than those at West ACC, this should be revealed by corresponding differences in the process and output measures.

4.1.2. Team inputs: A major factor in this research project was the differing team structure at South compared with North, East and West ACC. As team structure is potentially one of the main independent variables, it will be interesting to see if this can account for differences in team process and output variables. At South ACC the three CDE and one SS were assigned to either the strategy desk (whose role it was to anticipate demand over the next $24 \mathrm{~h}$ and take actions to meet the demand) and the operations desk (whose role it is to deal with demand and faults in real time), with two people working at each desk with responsibility for the whole area. At the other ACC each of the CDE worked in both operational and strategy roles for a non-overlapping third of the area whereas the SS performed mainly strategic tasks for the area as a whole. An illustration of the differences is shown in figure 3. 
Figure 2. CDE competency scores for the four ACC.

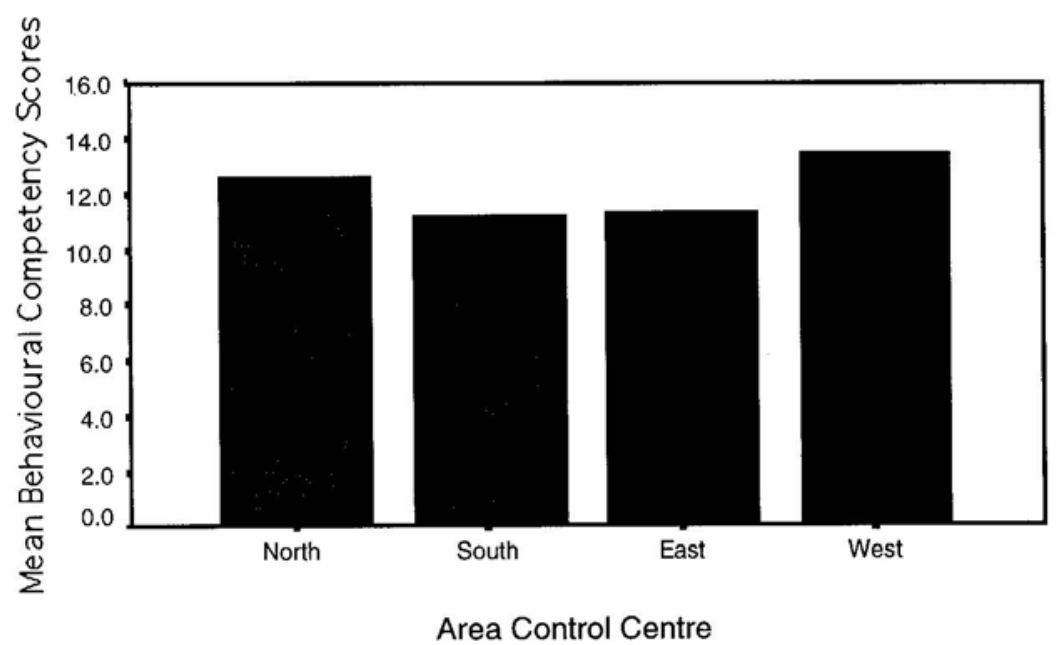

Figure 3. Differences between team structure.
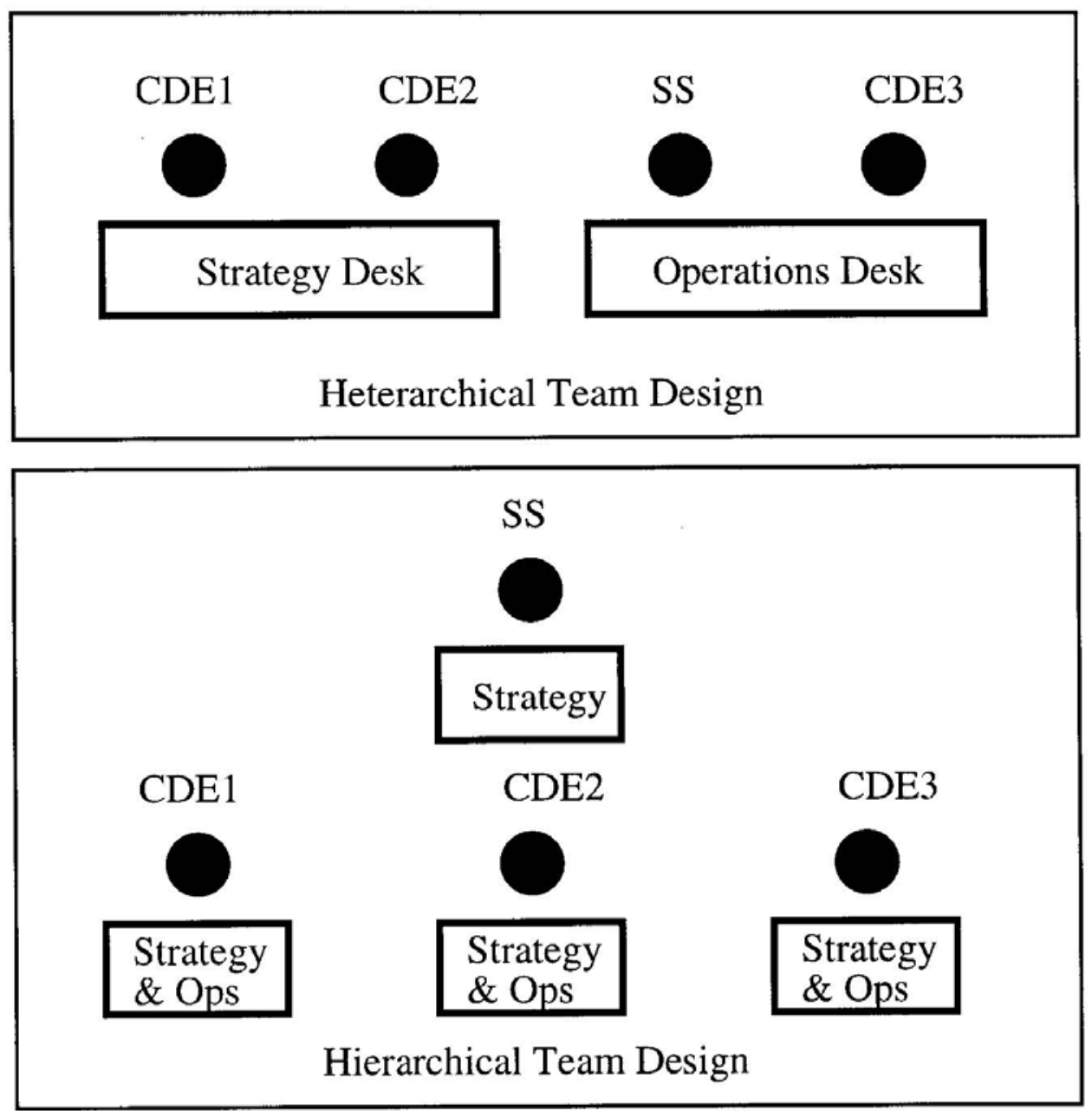
Table 2. Differences in team development and the time of year studied.

\begin{tabular}{llllc}
\hline Variable/ACC & North & South & East & West \\
\hline $\begin{array}{l}\text { Date } \\
\text { commissioned }\end{array}$ & October 1995 & July 1996 & October 1995 & June 1996 \\
Date studied & winter 1996 & winter 1996 & summer 1996 & summer 1996 \\
\hline $\begin{array}{l}\text { Team } \\
\text { development }\end{array}$ & 12 months & 3 months & 10 months & 2 months \\
\hline
\end{tabular}

As indicated, three main differences exist: role (the integrated SS role versus the separated SS role), task (mixed strategy and operations versus pure strategy or operations), and physical (separation of the SS from the CDE). Other differences between the four ACC should be born in mind, however. The se are the date that the ACC was commissioned, the time of year the study was undertaken and the time over which the team had evolved (i.e. the date of the study minus the date of the commissioning). These data are expressed in table 2.

4.1.3. Contextual inputs: The core job characteristics were analysed by ACC, by characteristic and for an interaction between $A C C$ and job characteristic. There was no significant interaction between $\mathrm{ACC}$ and job characteristics.

As figure 4 shows, the lowest rated job characteristics are task identity(the degree to which the job results in an identifiable and visible outcome) and feedback from agents (the degree to which the individual is provided with information from others about the effectiveness of their efforts).Both factors offer room for improving the intrinsic nature of work in all four ACC. People need feedback to reinforce the positive aspects of their work and help develop the weaker areas.

4.2.1. Analysis of movement in the ACC: The physical movement of CDE and SS around the control room was assessed as one indicator of the amount of interaction people had with each other, and therefore of their team working. The percentage of time that people spent at their workstation is shown in table 3.

Figure4. Core job characteristics in the four ACC

\section{Mean Score Across Area}

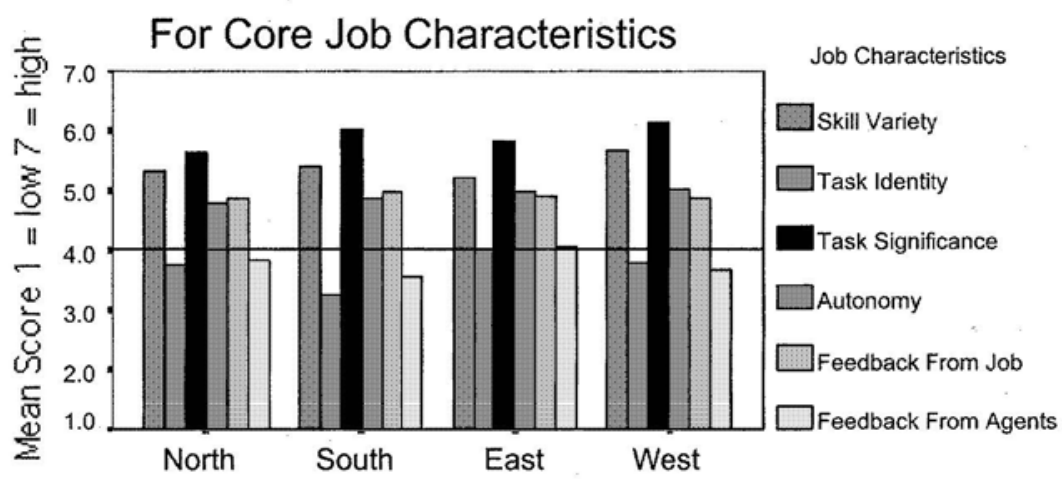

Area Control Centre 
As shown, there appears to be little difference between the ACC on the amount of time that CDE and SS spend at their workstations. These data are based on the observation of one afternoon shift only, and therefore should be treated accordingly. Nevertheless, the lack of difference between ACC can be confirmed statistically $(x 2=19.47, p=n s)$. Other areas in the $A C C$ in which people spent time include: filing, faxing, stand-alone PCs, printers, weather centre, meeting areas, and the kitchen. About5 $-10 \%$ of their time is spent outside the ACC. It is interesting to note that despite the differences in team structure at South ACC and the other ACC, this appears to have no effect on their physical movement around the ACC.

Table 3. Percentage of time that CDE and SS spend at their workstations

\begin{tabular}{lcccr}
\hline & North & South & East & West \\
\hline CDE 1 & 81 & 82 & 78 & 80 \\
CDE 2 & 88 & 92 & 68 & 96 \\
CDE 3 & 87 & 64 & 74 & 72 \\
SS & 77 & 74 & 54 & 78 \\
\hline
\end{tabular}

4.2.2. Direct observation: The most intensive method of the research project involved shadowing CDE and SS around their ACC. This provided very rich data on their activities. It should be noted that the observations at North and South ACC took place over the winter months (South,2 December 1996 - 27 February1997; North, 29 October 1996 - 15 January 1997) whereas the observations at East and West took place over the summer months (East, 1924 August 1996; West, 1620 September 1996). In addition, due to time limitations, only six shifts at one workstation were conducted at East andWestACC, whereas18 shifts were observed at North ACC and 24 shifts were observed at South ACC. For statistical comparison, the data have been normalized to take the different period of observation into account, but the time of year difference is likely to have an effect. Nevertheless, the comparison of North and South ACC is still legitimate. Reliability of the observational data was established further to the pilot study. A second observer was first trained in the classification system and then studied the videotape using the observer system. A sample shift was taken randomly from each area and the video classifications for time spent in each activity were compared with the manual classifications. Reliability was computed using the Spearman correlation coefficient. The results for each area are as follows: North $(q=0.97, p$ $<0.001)$, South $(0.98,<0.001)$, East $(0.97,<0.001)$ and West $(0.95,<0.001)$. These are very high, which lends confidence to the classification system.

The observational data were analysed by main tasks (i.e. shift handover, maintenance, problems, demand forecasting, servicing application functions and monitoring and controlling the system). The results of the statistical analysis for the main tasks are presented in table 4 .

Table 4. Analyses of main tasks at the ACC.

\begin{tabular}{lcccc}
\hline Task & $\mathrm{F}$ & d.f. & $p<$ & SheVeÂ (where $p<0.05)$ \\
\hline Shift handover & 2.69 & 3,50 & $\mathrm{~ns}$ & $\mathrm{n} / \mathrm{a}$ \\
Maintenance & 7.06 & 3,50 & 0.001 & North $>$ East, North $>$ South \\
Problems & 1.35 & 3,50 & $\mathrm{~ns}$ & $\mathrm{n} / \mathrm{a}$ \\
Demand forecasting & 0.87 & 3,50 & $\mathrm{~ns}$ & $\mathrm{n} / \mathrm{a}$ \\
Applications & 4.89 & 3,50 & 0.005 & South $>$ North, West $>$ North \\
Control and monitor & 13.96 & 3,50 & 0.0001 & North $>$ East, North $>$ West, \\
& & & & South $>$ East \\
\hline
\end{tabular}


Table 5. Mean (SD) times (min) for the statistically significant differences in activities.

\begin{tabular}{lcccc}
\hline Variable/ACC & North & South & East & West \\
\hline Maintenance & $53.3(19.9)$ & $29.6(17.5)$ & $34.7(14.8)$ & $27.7(16.6)$ \\
Applications & $54.1(22.2)$ & $99.2(46.5)$ & $73.3(18.1)$ & $108.5(62.9)$ \\
Control and monitor & $129.7(28.4)$ & $121.1(31.4)$ & $51.3(14.6)$ & $70.8(46.2)$ \\
\hline
\end{tabular}

The analysis shows that North ACC was engaged in a greater amount of maintenance activity than West and South (table 5). This may be attributed to physical aspects of the energy storage and distribution system. It is particularly worthy of note that while it maybe expected that a good deal of maintenance work is conducted in the summer months (the time that West ACC was observed) this might not be expected to be so prolific in the winter months(the time that North ACC was observed). South and West ACC service the applications functions (e.g. electronic messages) far more than North ACC (table 5). This is primarily due to the use of Lotus notes facilities at South and West ACC. The greater monitoring of the control system by North and South ACC is highly likely to be a time-of-year effect (table 5). North and South $A C C$ were observed during the winter months whereas East and West ACC were observed during the summer months.

\section{Breakdown of Activities Across Area} Showing Mean Time per Shift Activity Categories

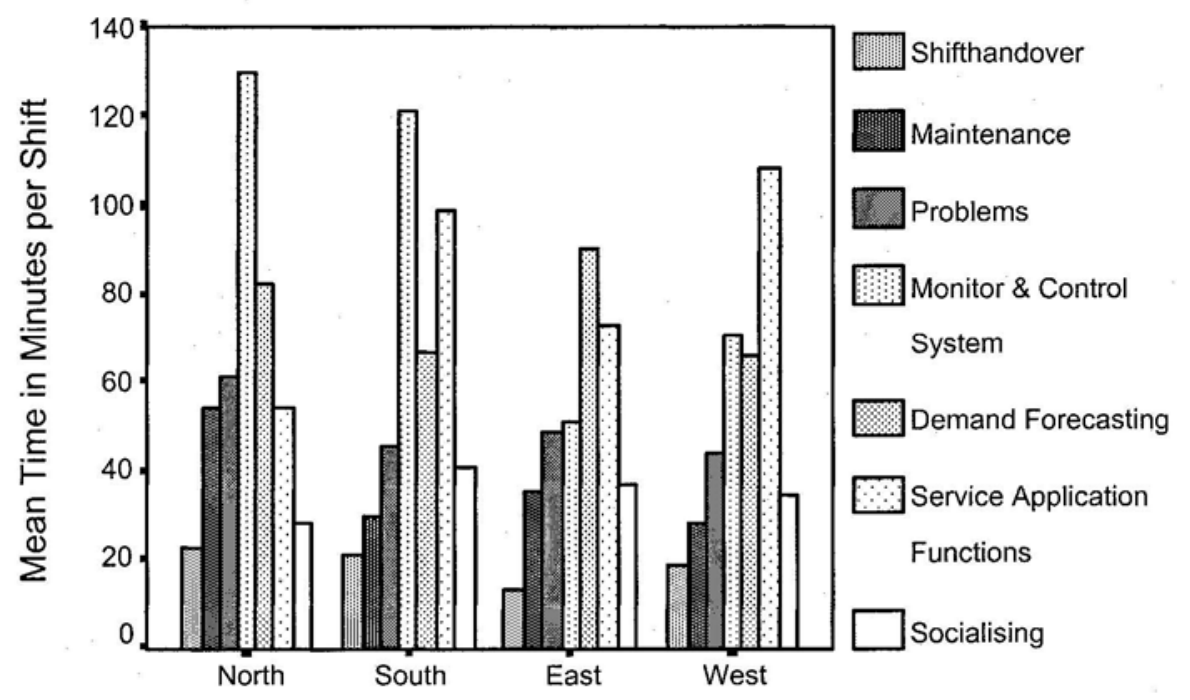

Area Control Centre

Figure 5. Main tasks in the four ACC

Table 6. Analysis of PASOD activities by ACC

\begin{tabular}{lcccc}
\hline Task & F & d.f. & $p<$ & Sheffe (where $p<0.05)$ \\
& & & & \\
\hline Planning & 8.37 & 3,50 & 0.0005 & North $>$ South, North $>$ East, North $>$ West \\
Awareness & 8.13 & 3,50 & 0.0005 & North $>$ East, North $>$ West, South $>$ East, \\
& & & & South $>$ West \\
Sharing & 8.34 & 3,50 & 0.0005 & South $>$ North, West $>$ North \\
Other & 4.74 & 3,50 & 0.01 & South $>$ North \\
Driven & 5.31 & 3,50 & 0.0005 & North $>$ South \\
\hline
\end{tabular}


As well as looking for differences in the main tasks across the area, the interaction between activities conducted with the main tasks was also explored. The main differences between ACC are indicated in figure5.

The generic activities were also analysed statistically. Generally, it was thought that it is better for ACC personnel to be engaged in planning, awareness and sharing activities rather than system driven activities, as this indicates proactive and anticipatory behaviour. Analysis of the PASOD activities is presented in table 6 .

From the analysis, North ACC spends a greater amount of time planning (e.g. activities that require strategic planning and driving the system such as forecasting demand, checking constraints, planning operations, issuing fault reports and completing a holder log summary) than the other ACC (table 7). North and South ACC spend a greater amount of their time in awareness functions (e.g. activities that maintain an awareness of system state, monitoring stock, monitoring alarm lists, checking telemetry, monitoring demand and intake)(table7).This may well be due to the timing of the observations, being winter at North and South and summer at East and West. West and South ACC spend a greater amount of their time in sharing functions (e.g. activities that share own and others knowledge of the system such as creating and editing an event log, sending e-mail or lotus notes, editing a handover log, putting information on a bulletin board, holding a discussion forum and providing training)than North ACC (table7). This may be due to the greater use of Lotus notes, applications and email facilities. South spends a greater amount of their time in other activities (e.g. project work and social communication) than North ACC (table 7). This may be an effect of the team structure and greater participation in project work. Finally, North ACC spends a greater amount of their time in driven functions(e.g. activities that driven by the system in real-time such as sending controls, answering the phone, acknowledging and analysing alarms and dealing with interruptions) than South (table 7). This may be an effect of team structure as well as the differences in plant and geography of the two ACC.

Table7. Means(SD) times(min) for PASOD activities.

\begin{tabular}{lrlcr}
\hline Variable/ACC & North & South & East & West \\
\hline Planning & $67.8(15.9)$ & $43.3(19.5)$ & $43.2(8.8)$ & $41.7(15.9)$ \\
Awareness & $133.4(23.5)$ & $132.4(37.3)$ & $84.0(20.8)$ & $80.5(33.6)$ \\
Sharing & $33.9(15.8)$ & $93.3(49.2)$ & $67.0(12.1)$ & $109.5(78.2)$ \\
Other & $73.5(21.2)$ & $100.4(29.8)$ & $106.2(21.8)$ & $98.7(22.1)$ \\
Driven & $174.9(36.1)$ & $129.4(41.2)$ & $133.8(26.3)$ & $122.0(55.1)$ \\
\hline
\end{tabular}

Table 8. Team working factors at the ACC.

\begin{tabular}{lcccc}
\hline \multicolumn{1}{c}{ Factor } & $\mathrm{F}$ & d.f. & $p<$ & Sheffe (where $p<0.05)$ \\
\hline Consensus & 6.86 & 3,116 & 0.003 & South $>$ North, East $>$ North, East $>$ West \\
Coordination & 0.64 & 3,116 & $\mathrm{~ns}$ & $\mathrm{n} / \mathrm{a}$ \\
Control & 1.20 & 3,116 & $\mathrm{~ns}$ & $\mathrm{n} / \mathrm{a}$ \\
Communication & 1.39 & 3,116 & $\mathrm{~ns}$ & $\mathrm{n} / \mathrm{a}$ \\
Cooperation & 2.79 & 3,116 & 0.05 & South $>$ East \\
Coaching & 0.87 & 3,116 & $\mathrm{~ns}$ & $\mathrm{n} / \mathrm{a}$ \\
Culture & 8.57 & 3,116 & 0.0001 & South $>$ West, South $>$ North, East $>$ West
\end{tabular}

4.2.3. Team working questionnaire: The results of the team working questionnaire show no main effect for $A C C(F 3,114=2.07, p=n s)$, but an interaction between the $A C C$ and the team working factors $(F 18,684=3.98, p<0.001)$. This means that some $A C C$ rated higher on some factors than others. A breakdown of the factors by ACC is shown in table 8 . 
The analysis shows that people at South ACC rate higher on the team working factors consensus, cooperation and culture (table 9 and figure 6).

This effect maybe attributed to the team structure at South ACC. East ACC also rates positively on consensus and culture compared with West. One explanation for this finding is that East have had more time together(i.e.10 months)when compared with West (who had only 2 months together at the time of the study). It can take several months before a team of people can begin to perform effectively together (Tuckman 1965).

4.3. Outputs from area control centres The outputs form the ACC were measured in terms of the outputs for the company (in terms of the critical success factors) and the outputs for the individual (in terms of job satisfaction). The critical success factors questionnaire was sent to $\mathrm{NCC}$ and districts and was used in the absence of any viable energy-system based measures of performance. However, this measure is justified on the basis that people's perception of degree to which the ACC are meeting their requirements are likely to be well informed and just as valid as any other measure. These judgements are unlikely to be contaminated by the effects of seasonal, geographical and diversity of plant upon the energy system.

Table9. Means(SD) for statistically significant team working questionnaire factors.

\begin{tabular}{lcccr}
\hline Variable/ACC & North & South & East & West \\
\hline Consensus & $5.1(1.8)$ & $6.3(1.3)$ & $6.5(1.1)$ & $5.4(1.5)$ \\
Cooperation & $6.6(1.2)$ & $7.0(1.3)$ & $6.1(1.3)$ & $6.3(1.2)$ \\
Culture & $5.3(1.6)$ & $6.5(1.1)$ & $5.8(1.0)$ & $4.8(1.4)$ \\
\hline
\end{tabular}

Figure 6. Teamwork factors in the four ACC.

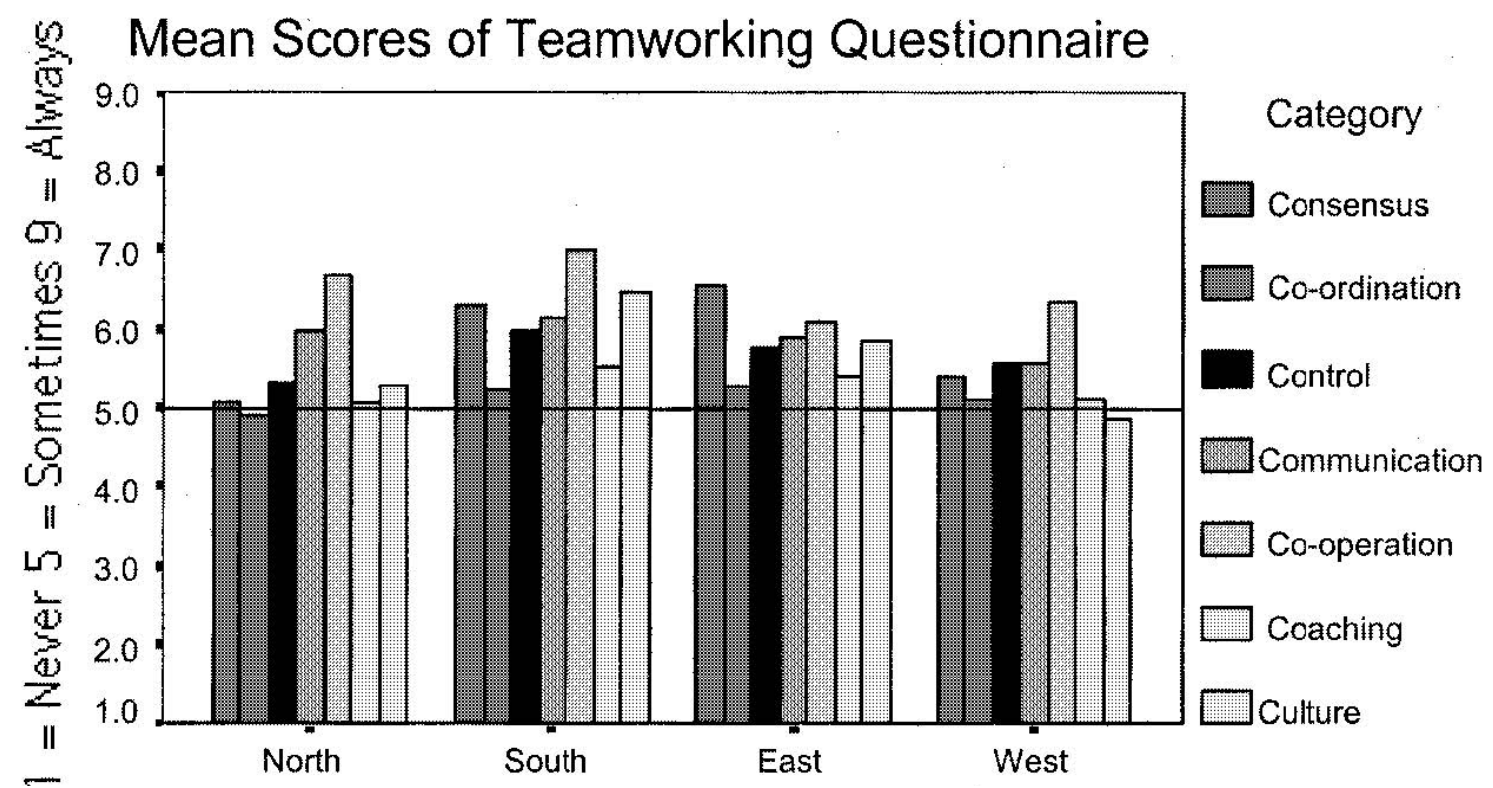

4.3.1. Critical success factors: The critical success factors questionnaire was completed by both districts and NCC. The picture from both of these groups is similar. The district response indicated that there was no statistically significant differences between the ACC (F3,102 = $1.5, p=n s)$, and there was no interaction between $A C C$ and factors $(F 18,612=1.75, p=n s)$. This means that the districts did not rate any difference between the ACC in any of the factors. 
The NCC response indicated that there was no statistically significant differences between the $\operatorname{ACC}(\mathrm{F} 3,47=0.649, \mathrm{p}=\mathrm{ns})$, and there was no interaction between $\mathrm{ACC}$ and factors (F18,282 $=1.22, p=n s$ ). This means that the NCC did not rate any difference between the ACC. However, the districts judge that, generally speaking, all ACC perform well on the critical success factors. West ACC appears below the scale mid-point on two factors(understanding need and communication). These are two areas that might be improved. All areas seem to be particularly well rated on the trust and caring/helpful factors.

4.3.2. Work and life satisfaction: There were no statistically significant differences between the ACC (F3,108 $=0.59, p=n s)$, and no interaction between ACC and factors (F27,972 = 1.31, $p=n s$ ). This means that there were no discernible differences in work and life satisfaction between the four areas. Although there were no differences between the ACC, the general picture is positive. The ACC personnel appear to enjoy a good level of work and life satisfaction, particularly when compared with other occupational groups (e.g. Warr et al. 1979).

4.4. Summary of results The main findings are summarized in table 10.

Table10. Summary of main findings.

\begin{tabular}{|c|c|c|}
\hline Factors & Variables & Results \\
\hline Input & $\begin{array}{l}\text { competencies } \\
\text { team development } \\
\text { time of year } \\
\text { team structure } \\
\text { core job characteristics }\end{array}$ & $\begin{array}{l}\text { West }>\text { South } \\
\text { North + East }>\text { South + West } \\
\text { winter (North + South) versus } \\
\text { summer (East + West) } \\
\text { hierarchy (North + East + West) } \\
\text { versus heterarchy } \\
\text { no significant differences }\end{array}$ \\
\hline Process & $\begin{array}{l}\text { physical movement } \\
\text { planning } \\
\text { awareness } \\
\text { sharing } \\
\text { other } \\
\text { driven } \\
\text { consensus } \\
\text { cooperation } \\
\text { culture }\end{array}$ & $\begin{array}{l}\text { no significant differences } \\
\text { North }>\text { South + East }+ \text { West } \\
\text { North + South }>\text { East }+ \text { West } \\
\text { South + West }>\text { North } \\
\text { South }>\text { North } \\
\text { North }>\text { South } \\
\text { South }>\text { North; East }>\text { North + } \\
\text { West } \\
\text { South }>\text { East } \\
\text { South }>\text { North + West; East }> \\
\text { West }\end{array}$ \\
\hline Output & $\begin{array}{l}\text { critical success factors } \\
\text { work/life satisfaction }\end{array}$ & $\begin{array}{l}\text { no significant differences } \\
\text { no significant differences }\end{array}$ \\
\hline
\end{tabular}

\section{General discussion and conclusions}

This study sought to conduct empirical research into real teams. Research of this nature is always opportunistic and it is difficult to control the variables to the same degree as laboratory studies. Nevertheless, as Vincente (1997) notes, one should not be apologetic for field studies. The case presented within this paper offers the opportunity to explore the effects of differences between teams as well as the general consideration of changes in working together with the introduction of new technology. It is fair to say that there were not great differences between the four ACC, but that may not be too surprising given that the SCADA technology was identical and there had been a good deal of effort from the organization to harmonize operations. There remained three identifiable differences, however. Namely, the time of- year the studies were undertaken (i.e. winter or summer), the stage of team 
development (i.e. $<2$ months or $>10$ months) and the structure of the team configuration (i.e. hierarchy or heterarchy). The time-of-year differences are perhaps the least interesting but do highlight differences in activities associated with continuous processes. It was observed that the ACC studied in winter were engaged in more 'planning' and 'awareness' activities (i.e. information-gathering behaviours) than those observed in the summer months. Rather more interesting is the finding that newer ACC teams engage in more 'information 'sharing' activities than their more mature counterparts. This may re ${ }^{-}$ect their stage of development, and as time progresses less of these activities might be observed as the individuals get to know and trust each other. Finally, the structural differences between the teams also appear to have had some effect on the activities of the teams. North ACC (a hierarchical team) spent a greater amount of time in system 'driven' activities than South ACC (a heterarchical team). Hollnagel (1993) argues that strategic control (e.g. 'planning' and 'awareness' activities) is superior to reactive control (e.g. system 'driven' activities). Others have investigated the effects of team structure on performance. The two main strands of this other research have concentrated on lines of communication (Katz and Kahn 1978) and task loading (Stammers and Hallam 1985). In a study comparing different communication structures, Kawano et al. (1991) indicated how team performance might be affected by communication styles. They argue that tight-coupling and bottom-up communication (i.e. where lines of communication are unconstrained) leads to superior performance than loose coupling and top-down communication (i.e. where communication is directed through a hierarchy). They proposed that this is due, in part, to reduction in bureaucracy and, in part, by improved communication channels providing the possibility for feedback. In direct contrast, Katz and Kahn (1978) argue that the efficiency of communication systems can be measured in terms of the number of communication links. In general, fewer links lead to greater efficiency. One essential difference was introduced into one of the experimental conditions by virtue of the location, is that the South ACC embodied an all-channel communication system whereas the other North ACC embodied wheel communication systems. The wheel network is supposed to be the optimal communication network design. Typically these designs lead to faster task performance and fewer errors. Drawbacks associated with wheel networks are that the individual at the hub (i.e. the central person through whom all communications must pass, the SS) can become overloaded, may censor communications and can have a strong influence on the decision-making. Research evidence has suggested however, that the wheel design can also lead to reductions in group satisfaction and isolation of individual group members (Katz and Kahn 1978).

This could explain the differing perceptions of team working in the hierarchical and heterarchical teams, most notably that South ACC reported greater perceptions of team working. The all-channel communication network, such as that at South ACC, makes informal communication more likely. Kraut et al. (1990) stressed the importance of informal communication. Informal communication is a loosely defined concept, but may be thought of as unscheduled communication, between random participants with no prearranged agenda, which is highly interactive and rich. In a study of a research and development organization Kraut et al. (1990) found that $85 \%$ of all communication was informal, of which $50 \%$ occurred because colleagues were physically proximate. They found that as the opportunity for informal communication with colleagues increased, so did familiarity with them and their work, and liking for them and their work. They concluded that proximity leads to increased frequency of communication in general, and of informal communication specifically. Proximate colleagues have more opportunity for spontaneous conversations, which leads to greater familiarity and increased respect. They proposed that proximity therefore is likely to be a powerful facilitator for successful working relationships, since familiarity should enable them 
to share perspectives. The implications for this study is that by working on the same area of the system, South ACC may have increase physical and task proximity than their colleagues in North, East and West ACC, who work on separate areas of the system. In addition, the organization of the teams might also be influencing the degree of team activity. Stammers and Hallam (1985) reported a series of case studies investigating task demands and team organization in control room (air traffic and emergency services) domains. They suggested that optimal task separation would largely depend on the operational system. They identified two main team organization methods as vertical (e.g. whole task separation) and horizontal (e.g.sharing tasks between people). In vertical organization, sets of tasks are allocated to one operator. Horizontal organization means that any of the operators can carry out the tasks. These two principal methods of team design are illustrated in table 11. While Stammers and Hallam (1985) emphasized the pure vertical and horizontal task organization, they allowed for hybrids of the same (table 11).

In the vertical hybrid (North ACC: the hierarchical design), the SS is predominately involved with task $A$, whereas the $C D E$ are predominately involved with tasks $C E$ respectively. In the horizontal organization the $S S$ is predominately involved with tasks $A$ and $B$ (sharing task $B$ with CDE 1), and two of the CDE are sharing tasks CE. Additionally, in times of high operational demand, the SS and CDE 1 assist CDE 2 and 3. From their studies, Stammers and Hallam (1985) drew some conclusions about the design of team organization. They suggested that various mixes of vertical or horizontal team structures were likely to be possible and should be assessed. They also proposed that is also important to try to build inexibility, to allow team organization to vary under changing task demands (e.g. as in South ACC).

Table 11. Forms of team organization with four people and five tasks.

\begin{tabular}{ccccc}
\hline Tasks & SS & CDE 1 & CDE 2 & CDE 3 \\
\hline Vertical hybrid & $\mathrm{A}+0.25(\mathrm{~B})$ & $0.25(\mathrm{~B})+\mathrm{X}$ & $0.25(\mathrm{~B})+\mathrm{Y}$ & $0.25(\mathrm{~B})+\mathrm{Z}$ \\
Horizontal hybrid & $\mathrm{A}+0.5(\mathrm{~B})$ & $0.5(\mathrm{~B})$ & $0.5(\mathrm{X}, \mathrm{Y}, \mathrm{Z})$ & $0.5(\mathrm{X}, \mathrm{Y}, \mathrm{Z})$ \\
\hline
\end{tabular}

Tasks: overall responsibility $(A)$, strategy $(B)$, control of local distribution zones $(X, Y, Z)$.

This applied research project took a snapshot of four ACC at various stages of development following a considerable organizational change and the introduction of new technology. There have been many studies showing the pitfalls associated with the introduction of new technology (Hackman and Oldham 1980, Eason 1982, Buchanan and Boddy 1983). Blackler and Brown (1986) characterized three potential strategies as muddle-through, tasks-andtechnology and organization and-end-user approaches. While no organizations strategy is likely to fall wholly into one of these, those that predominately use the first two are likely to be less successful than those using the latter. The company studied took a largely tasks-and technology approach, although it also undertook a fair amount of consultation with end users. Previous research has distinguished between end-user consultation and designing for endusers from an ergonomics perspective. While participative design is a desirable approach, it is not sufficient to guarantee success. Coupled with ergonomic methods in design it can, however, lead to considerable improvements over the tasks-and-technology approach. Studies from a socio-technical systems perspective have demonstrated the benefits of usercentred design (Trist and Bamforth 1951). This approach puts at least as much emphasis on the social work systems as was traditionally placed on design of technical systems.

It is no small irony that, in common with other studies, this study was undertaken after the organization changes had taken place (Trist et al. 1977, Cummings 1980). While it is admirable that organizations want to gauge how successful they have been, rather more benefit could be reaped if measures of previous generations of systems are taken for baseline 
data. Most ergonomists will recognize the difficulties in gaining access to organizations early enough to be involved in the process of change. Evaluative studies such as this can only hope to offer remedial fixes $\mathrm{n}$ the short-term, but will, optimistically, convince organization of benefits associated with ergonomics interventions in the longer term.

\section{Acknowledgements}

The authors thank all those who participated in the project at the company Area Control Centres, districts and National Control Centre, and Jaquita Britton for her help with collecting data, Abigail Laybourne and Tamsin Coley for help in compiling data files, Dr Tony Roberts for advice on inferential statistics and Peter Chambers, John Piggott and Mark Young for comments on earlier drafts. Finally, they are indebted to three anonymous reviewers who helped the focus of the paper and who provided many insightful and valuable comments. The views expressed here are those of the authors and should not necessarily be attributed to the company involved.

ACKOFF, R. L. and EMERY, F. E. 1972, On Purposeful Systems (London: Tavistock). ASHLEIGH, M. J. and STANTON, N. A. 1996, A systems analysis of team working in control rooms: methodology considered, in D. Harris (ed.), Engineering Psychology and Cognitive Ergonomics Volume II (Aldershot: Ashgate), 33- 38.

BLACKLER, F. and BROWN, C. 1986, Alternative models to guide the design and introduction of new information technology into work organizations, Journal of Occupational Psychology, 59, 287- 313.

BUCHANAN, D. A. and BODDY, D. 1983, Advanced technology and the quality of working life:

the effects of computerised controls on biscuit-making operators, Journal of Occupational Psychology, 56, 109- 119.

1208 N. A. Stanton and M. J. Ashleigh

Downloaded By: [Brunel University] At: 13:22 1 February 2008

CHAPANIS, A. 1959, Research Techniques in Human Engineering (Baltimore: Johns Hopkins University Press).

CUMMINGS, T. 1980, Systems Theory for Organizational Development (Chichester: Wiley). DRURY, C. G. 1995, Methods for direct observation of performance, in J. Wilson and N. Corlett (eds), Evaluation of Human Work, 2nd edn (London: Taylor \& Francis) 45- 68. DULEWICZ, V. 1989, Assessment centres as the route to competence, Personnel Management,

November, 56- 59.

EASON, K. D. 1982, The process of introducing new technology, Behaviour and Information Technology, 1, 197- 213.

FOUSHEE, H. C. and HELMREICH, R. L. 1988, Group interaction and flight crew performance, in

Human Factors in Aviation (New York: Academic Press).

GLENDON, A. I., STANTON, N. A. and HARRISON, D. 1994, Factor analysing a performance

shaping concepts questionnaire, in S. Robertson (ed.), Contemporary Ergonomics 1994 (London: Taylor \& Francis), 340- 345.

GUZZO, R A. and SHEA, G. P 1992, Group performance and inter-group relations in organizations, in M. D. Dunnette and L. M. Hough (eds), Handbook of Industrial and Organizational Psychology $Ð$ Volume 3 (Palo Alto: Consulting Psychology Press), 269313.

HACKMAN, J. R. and OLDHAM, G. 1980, Work Redesign (Addison-Wesley).

HETTENHAUS, J. R. 1992, Changing the way people work: a sociotechnical approach to computer-integrated manufacturing in a process industry, in $\mathrm{H}$. Kragt (ed.), Enhancing Industrial performance (London: Taylor \& Francis), 179- 198.

HOLLNAGEL, E. 1993, Human Reliability Analysis: Context and Control (London: Academic Press).

KATZ, D. and KAHN, R. L. 1978, The Social Psychology of Organizations (New York: Wiley). 
KAWANO, R., FUJIIE, M., UJITA, H., KUBOTA, R., YOSHIMURA, S. and OHTSUKA, T. 1991, Plant

operators behaviour in emergency situations by using training simulators, in $\mathrm{Y}$.

Queinnec and F. Daniellou (eds), Designing for Everyone (London: Taylor \& Francis).

KEMP, G. O. and MCCLELLAND, D. C. 1986, What characterises intelligent functioning among

senior managers?, in R. J. Sternberg and R. K. Wagner (eds), Practical Intelligence

(Cambridge: Cambridge University Press).

KRAUT, R. E., FISH, R. S., ROOT, R. W. and CHALFONT, B. L. 1990, Informal

communication in

organizations: form, function, and technology, in S. Oskamp and S. Spacapan (eds),

Peoples Reactions to Technology. In Factories, OYces and Aerospace. The Claremont

Symposium on Applied Social Psychology (London: Sage).

LOCKETT, M. and SPEAR, R. 1980, Organizations as Systems (Milton Keynes: Open

University

Press).

STAMMERS, R. B. and HALLAM, J. 1985, Task allocation and the balance of load in the multiman - machine system: some case studies, Applied Ergonomics, 16, 251- 257.

STANTON, N. A. 1996, Human Factors in Nuclear Safety (London: Taylor \& Francis).

STANTON, N. A. and ASHLEIGH, M. J. 1999, A systems analysis of team working in human supervisory control, in D. Harris (ed.), Engineering Psychology and Cognitive

Ergonomics Volume Four (Aldershot: Ashgate), 29 - 35.

TRIST, E. L. and BAMFORTH, K. W. 1951, Some social psychological consequences of the longwall

method of coal getting, Human Relations, 4, 3- 38.

TRIST, E. L., SUSMAN, G. I. and BROWN, G. R. 1977, An experiment in autonomous working in

an American underground coal mine, Human Relations, 30, 201- 236.

TUCKMAN, B. 1965, Development sequence in small groups, Psychological Bulletin, 63, 384 $-99$

VINCENTE, K. J. 1997, Heeding the legacy of Miester, Brunswick and Gibson: toward a broader

view of human factors research, Human Factors, 39, 323- 328.

VON BERTALANFFY, L. 1950, The theory of open systems in physics and biology, Science, 13 ,

23- 29.

WARR, P., COOK, J. and WALL, T. 1979, Scales for the measurement of some work attitudes and

aspects of psychological well-being, Journal of Occupational Psychology, 52, 129- 148.

WEST, M. A. and ANDERSON, N. R. 1996, Innovation in management teams, Journal of Applied

Psychology, 81, 680- 693.

WOODS, D. D. 1987, Technology alone is not enough: reducing the potential for disaster in risky technologies, in Human Reliability in Nuclear Power (London: IBC). 